\title{
Cutting-induced end surface effect on compressive behaviour of aluminium foams
}

DOI:

10.1016/j.euromechsol.2019.02.015

\section{Document Version}

Accepted author manuscript

Link to publication record in Manchester Research Explorer

\section{Citation for published version (APA):}

Meng, K., Chai, C. G., Sun, Y., Wang, W., Wang, Q., \& Li, Q. M. (2019). Cutting-induced end surface effect on compressive behaviour of aluminium foams. European Journal of Mechanics, A/Solids, 75, 410-418.

https://doi.org/10.1016/j.euromechsol.2019.02.015

\section{Published in:}

European Journal of Mechanics, A/Solids

\section{Citing this paper}

Please note that where the full-text provided on Manchester Research Explorer is the Author Accepted Manuscript or Proof version this may differ from the final Published version. If citing, it is advised that you check and use the publisher's definitive version.

\section{General rights}

Copyright and moral rights for the publications made accessible in the Research Explorer are retained by the authors and/or other copyright owners and it is a condition of accessing publications that users recognise and abide by the legal requirements associated with these rights.

\section{Takedown policy}

If you believe that this document breaches copyright please refer to the University of Manchester's Takedown Procedures [http://man.ac.uk/04Y6Bo] or contact uml.scholarlycommunications@manchester.ac.uk providing relevant details, so we can investigate your claim.

\section{OPEN ACCESS}




\section{Accepted Manuscript}

Cutting-induced end surface effect on compressive behaviour of aluminium foams

K.P. Meng, C.G. Chai, Y.L. Sun, W. Wang, Q.Y. Wang, Q.M. Li

PII: S0997-7538(18)30681-8

DOI: https://doi.org/10.1016/j.euromechsol.2019.02.015

Reference: EJMSOL 3749

To appear in: European Journal of Mechanics / A Solids

Received Date: 8 September 2018

Revised Date: 18 February 2019

Accepted Date: 21 February 2019

Please cite this article as: Meng, K.P., Chai, C.G., Sun, Y.L., Wang, W., Wang, Q.Y., Li, Q.M., Cuttinginduced end surface effect on compressive behaviour of aluminium foams, European Journal of Mechanics / A Solids (2019), doi: https://doi.org/10.1016/j.euromechsol.2019.02.015.

This is a PDF file of an unedited manuscript that has been accepted for publication. As a service to our customers we are providing this early version of the manuscript. The manuscript will undergo copyediting, typesetting, and review of the resulting proof before it is published in its final form. Please note that during the production process errors may be discovered which could affect the content, and all legal disclaimers that apply to the journal pertain. 

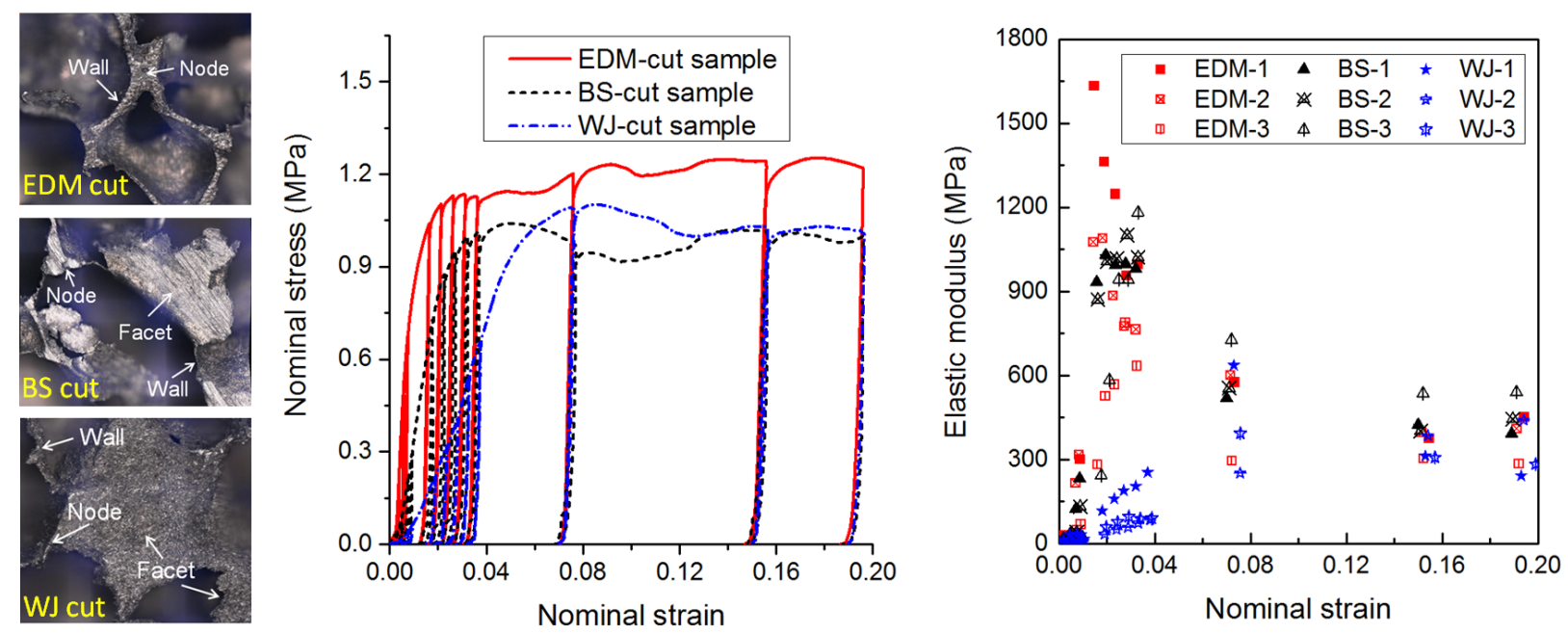


\title{
Cutting-induced end surface effect on compressive behaviour of aluminium foams
}

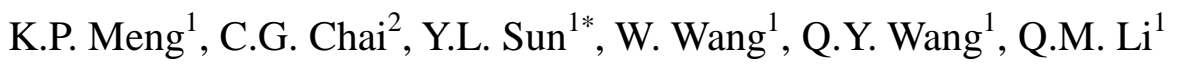 \\ ${ }^{1}$ School of Mechanical, Aerospace and Civil Engineering, The University of Manchester, \\ Sackville Street, Manchester M13 9PL, UK \\ ${ }^{2}$ Institute of Chemical Materials, CAEP, Mianyang, Sichuan 621900, PR China
}

\begin{abstract}
Three cutting methods, i.e. electrical discharge machining (EDM), band saw (BS) and water jet (WJ), were used to prepare cuboid samples of closed-cell aluminium Alporas foam. On the end surfaces of the prepared samples, local roughness of mesoscopic structural components (i.e. cell wall, node and facet) and global roughness for the entire cut surface were measured using confocal microscopy. Furthermore, quasi-static uniaxial compression tests were performed with intermittent unloading-reloading. In the initial stage of compression, the measured loading stiffness and unloading elastic modulus are highest, intermediate and lowest for the EDM-cut, BS-cut and WJ-cut samples, respectively. This difference in measured compressive properties has been correlated with the difference in end-surface roughness associated with different cutting methods. However, the peak and plateau of compressive stress and the unloading elastic modulus in the plateau stage are insensitive to cutting method. An analytical model has been developed to elucidate the observed compressive behaviour and shed light on the responsible mechanisms.
\end{abstract}

Keywords: Cellular materials; compression; stiffness; Young's modulus; cutting; surface unevenness

\section{Introduction}

As a new class of light-weight and multi-functional materials relative to traditional metals and alloys, metal foams have been increasingly used in various engineering applications across many industrial sectors, such as aerospace (Ryan and Christiansen, 2013), automobile (Banhart et al., 2017) and healthcare (Gibson et al., 2010). The unique cell structures of metal foams give rise to extraordinary material properties. For instance, they possess low density (Gibson and Ashby, 1997), high capacity of energy absorption and load mitigation (Islam et al., 2017), and advantageous capability for insulating heat (Hofmann and Kaudelka, 2016) and sound (Lu et al., 1999). Their compressive properties are of particular importance when they are used to

\footnotetext{
* Corresponding author. yongle.sun@manchester.ac.uk; sunyongletl@gmail.com (Y.L. Sun)
} 
absorb energy and mitigate impact/blast loads (Sun and Li, 2018).

The compressive properties of metal foams are closely associated with their cell structures which can be altered during machining and processing. For instance, cutting can alter the characteristics of mesoscopic structural components on cut surfaces. Therefore, proper preparation of test samples is crucial for the accurate measurement of compressive properties of metal foams. Ashby et al. (2000) recommended electrical discharge machining (EDM) for preparation of metal foam samples. Indeed, a comparison study on aluminium foam sample surfaces produced by different cutting methods confirms that EDM provides good cut quality in terms of surface cleanliness and flatness (Krajewski and Nowacki, 2013). However, a recent experimental study on the geometrical characteristics of cut surfaces of $\mathrm{AlSi}-\mathrm{SiC}$ composite foam shows that EDM cutting still generates high roughness of cut edges (Krajewski and Nowacki, 2015). With a lack of standard procedure for sample preparation, compressive properties of metal foams have been measured using samples prepared by different cutting methods. For instance, Andrews et al. (2001) used a band saw to cut bulk aluminium foam into different samples with appropriate dimensions for compression tests; Markaki and Clyne (2001) employed EDM for preparation of aluminium foam samples to ensure the cleanliness and flatness of the cut surfaces.

Geometrical and structural characterisation of the cut surfaces of metal foams has been conducted in previous research. For instance, Krajewski and Nowacki $(2013 ; 2015)$ considered a variety of cutting methods (e.g. EDM, laser, plasma, saw and water jet) in preparation of AlSi-based foam samples, and they investigated the influence of different cutting methods on the microstructure, profile and roughness of cut edges by macroscopic and microscopic image analyses, but the geometrical and structural parameters of cut surfaces were not correlated with the measured material properties of the studied foam. Recently, Sun et al. (2016a) demonstrated the role of the mesoscopic unevenness of cut surfaces in the measured exceptional elastic moduli of ductile and quasi-brittle foam samples prepared by EDM and mechanical cutting processes. Codolini et al. (2017) observed similar effect of cut surfaces on the measured mechanical properties of polymers. However, the quantitative correlation between the cut-surface roughness and compressive behaviour of aluminium foams has not been established.

In this study, both local and global roughness of the end surfaces (with unit normals parallel to the compression direction) of closed-cell aluminium foam samples were measured and compared using confocal optical microscopy. The foam samples were prepared by three cutting methods, i.e. EDM, band saw (BS) and water jet (WJ). Furthermore, a series of quasi-static 
uniaxial compression tests with intermittent unloading-reloading were conducted on the prepared foam samples with different height values. The stress-strain relationship, compressive strength and unloading elastic modulus are determined, and the effect of cut surface on the compressive behaviour of the aluminium foam is analysed and discussed.

\section{Material and methods}

\subsection{Closed-cell aluminium foam}

Closed-cell aluminium Alporas foam was used in this study, which is a commercial product (Shinko Wire Co. Ltd) manufactured by a batch casting process (Miyoshi et al., 2000). During the manufacturing, $1.5 \mathrm{wt} . \% \mathrm{Ca}$ (thickening agent) is mixed into the molten aluminium at 680 ${ }^{\circ} \mathrm{C}$, and then 1.6 wt.\% $\mathrm{TiH}_{2}$, as a blowing agent, is mixed with the thickened aluminium alloy in a casting mould to produce the foam structure. The Alporas foam is regarded as most "homogeneous" among different types of aluminium foams (Banhart, 2001).

Cuboid samples with height values of $20 \mathrm{~mm}$ and $40 \mathrm{~mm}$ were prepared using different cutting methods, while all the samples had a square cross-section with lateral dimensions of 40 $\mathrm{mm} \times 40 \mathrm{~mm}$. They were divided into three categories in terms of cutting method. Three samples under each category were tested to ensure repeatability. Dimensions and relative densities of the prepared samples are presented in Table 1. The average cell size is $2.8-4.5 \mathrm{~mm}$ for Alporas foam with relative density ranging from 6.5\% to $12.8 \%$ (Miyoshi et al., 2000; Sugimura et al., 1997; Triawan et al., 2012) and the potential effect of the number of cells in a sample on measured bulk properties can be neglected for the dimensions of the prepared samples, particularly for the samples with a height of $40 \mathrm{~mm}$ (Jeon and Asahina, 2005).

Table 1 Dimensions and relative densities of Alporas foam samples

\begin{tabular}{|c|c|c|c|c|c|c|c|}
\hline \multirow{2}{*}{ Height } & \multirow{2}{*}{ Group } & \multicolumn{3}{|c|}{ Dimensions $(\mathrm{mm})$} & \multicolumn{3}{|c|}{ Relative densities (\%) } \\
\hline & & EDM & $\mathrm{BS}$ & WJ & EDM & $\mathrm{BS}$ & WJ \\
\hline \multirow{3}{*}{$20 \mathrm{~mm}$} & 1 & $19.9 \times 41.0 \times 40.0$ & $20.3 \times 40.0 \times 40.2$ & $20.0 \times 40.0 \times 40.0$ & 7.0 & 7.8 & 7.5 \\
\hline & 2 & $20.0 \times 40.0 \times 40.0$ & $20.2 \times 40.6 \times 40.0$ & $19.8 \times 39.9 \times 40.0$ & 8.4 & 7.2 & 8.4 \\
\hline & 3 & $20.0 \times 40.0 \times 40.0$ & $20.3 \times 40.0 \times 40.2$ & $19.2 \times 40.0 \times 43.4$ & 6.9 & 7.5 & 8.1 \\
\hline \multirow{3}{*}{$40 \mathrm{~mm}$} & 1 & $40.0 \times 40.0 \times 40.0$ & $40.2 \times 40.3 \times 40.0$ & $40.0 \times 39.3 \times 40.0$ & 7.0 & 7.0 & 7.4 \\
\hline & 2 & $40.0 \times 40.0 \times 40.0$ & $40.2 \times 40.3 \times 40.0$ & $40.0 \times 39.9 \times 40.0$ & 7.8 & 7.7 & 8.4 \\
\hline & 3 & $40.3 \times 40.0 \times 40.1$ & $40.1 \times 40.0 \times 40.3$ & $39.9 \times 40.0 \times 39.4$ & 7.9 & 7.7 & 8.0 \\
\hline
\end{tabular}

Note: In following sections, EDM-H20-1, BS-H20-1 and WJ-H20-1 denote the samples with a height of 
$20 \mathrm{~mm}$, which were prepared using electrical discharge machining, band saw and water jet, respectively, in group 1. Similar convention applies to the samples of groups 2 and 3 prepared by different cutting methods. For samples with a height of $40 \mathrm{~mm}$, the "H20" is replaced with "H40", while the rest of the convention is same.

\subsection{Cutting methods and cut-surface characterisation}

EDM, BS and WJ cutting processes were employed to prepare the foam samples. The equipment configuration and process parameters for cutting bulk aluminium Alporas foam are summarised in Tables 2-4. During the EDM cutting process, the aluminium base material of Alporas foam was removed by rapid recurring current discharges, and the wire electrode and the foam sample were separated by deionised water. BS cutting employed a sharp blade consisting of toothed steel to cut the foam sample and it has advantages to produce uniform cutting as a result of an evenly distributed tooth load. WJ cutting utilised a high-pressure jet of water with abrasive blasting, and its working temperature is relatively low, which is beneficial to restrain thermal effect on the machined aluminium base material. The samples prepared by the three cutting methods all meet the designed macroscopic dimensions within acceptable experimental uncertainty, as shown in Table 1.

Table 2 Equipment configuration and process parameters for EDM cutting.

\begin{tabular}{|c|c|c|c|c|c|c|}
\hline Machine & Manufacturer & $\begin{array}{l}\text { Working } \\
\text { electrode } \\
\text { dimension }\end{array}$ & $\begin{array}{l}\text { Dielectric } \\
\text { fluid }\end{array}$ & $\begin{array}{l}\text { Cutting } \\
\text { speed }\end{array}$ & $\begin{array}{l}\text { Nozzle-to-material } \\
\text { distance }\end{array}$ & $\begin{array}{l}\text { Nozzle } \\
\text { diameter }\end{array}$ \\
\hline $\begin{array}{l}\text { AgieCharmilles } \\
\text { CUT } 200 \mathrm{Sp}\end{array}$ & $\begin{array}{l}\text { GF Machining } \\
\text { Solutions }\end{array}$ & $0.25 \mathrm{~mm}$ & $\begin{array}{l}\text { Deionised } \\
\text { Water }\end{array}$ & $\begin{array}{l}3.36 \\
\mathrm{~mm} / \mathrm{min}\end{array}$ & $40 \mathrm{~mm}$ & $0.25 \mathrm{~mm}$ \\
\hline
\end{tabular}

Table 3 Equipment configuration and process parameters for BS cutting.

\begin{tabular}{lllll}
\hline Machine & Manufacturer & Cutting speed & $\begin{array}{l}\text { Blade } \\
\text { dimensions }\end{array}$ & Electric supply \\
\hline $\begin{array}{l}\text { Addison saws } \\
\text { V-4012H }\end{array}$ & T-JAW Machinery & $\begin{array}{l}300 \text { feet per } \\
\text { minute }\end{array}$ & $20 \times 1 \mathrm{~mm}$ & $400 \mathrm{~V}$ \\
\hline
\end{tabular}

Table 4 Equipment configuration and process parameters for WJ cutting.

\begin{tabular}{llllll}
\hline Machine & Manufacturer & $\begin{array}{l}\text { Cutting } \\
\text { speed }\end{array}$ & $\begin{array}{l}\text { Water } \\
\text { pressure }\end{array}$ & Abrasive & $\begin{array}{l}\text { Abrasive } \\
\text { flow rate }\end{array}$ \\
\hline $\begin{array}{l}\text { Waterjet model } \\
712655-1\end{array}$ & Flow & $2.4 \mathrm{~mm} / \mathrm{s}$ & $300 \mathrm{bar}$ & $\begin{array}{l}\text { Garnet } 120 \\
\text { mesh }\end{array}$ & $0.32 \mathrm{~g} / \mathrm{s}$ \\
\hline
\end{tabular}


Confocal microscopy has been demonstrated most suitable to quantify the surface structure of metal foams (Krajewski and Nowacki, 2015). Therefore, it was employed here to digitally image the foam sample in 3D so as to measure roughness. The cut surfaces on the sample ends are of major interest for the characterisation, since compressive properties were determined through applying an axial compressive load via contact between the sample ends and loading platens. A confocal optical microscope (KEYENCE VHX-5000) was used to perform a high-resolution 3D scanning over the cut surfaces of foam samples. Roughness measurements were performed in two directions parallel to the sample edges within the cut surface, using a series of contour lines.

In each measurement process, thirty lines extracted from the magnified image of the region of interest (ROI) were considered in each direction parallel to the sample edge on the cut surface, with prescribed intervals between the measurement points. The averaged roughness $R_{\mathrm{a}}$ of a ROI was calculated according to the following equations (ISO, 1997):

$$
\begin{gathered}
\sum_{k=1}^{n}\left(x_{k+1}-x_{k}\right) h_{k}=h_{A} \cdot\left(x_{n+1}-x_{1}\right) \\
\sum_{k=1}^{n}\left(x_{k+1}-x_{k}\right)\left|h_{k}-h_{A}\right|=R_{a} \cdot\left(x_{n+1}-x_{1}\right)
\end{gathered}
$$

where $n$ is the number of measurement points (ranging from 584 to 1599 for different lines, depending on the solid content covered by the corresponding lines), $x_{k}$ is the position of point $k$ in a line, $h_{k}$ is the measured height of point $k$, and $h_{A}$ is the average height of all points in the line. Eq. (1) is used to calculate $h_{A}$ which is used in Eq. (2) for calculation of roughness $R_{\mathrm{a}}$. It should be noted that the cut surface is defined within a range of measured height (a height range of $200 \mu \mathrm{m}$ is adopted in this study).

\subsection{Compression test}

A universal testing machine with a load capacity of $10 \mathrm{kN}$ (Zwick Roell Z010) was used for quasi-static uniaxial compression tests on foam samples. The downward loading speed was set to be $2 \times 10^{-5} \mathrm{~m} / \mathrm{s}$ and $4 \times 10^{-5} \mathrm{~m} / \mathrm{s}$ for the foam samples with height values of $20 \mathrm{~mm}$ and 40 $\mathrm{mm}$, respectively, corresponding to a nominal strain-rate of $1 \times 10^{-3} \mathrm{~s}^{-1}$. The nominal strain is obtained to be the ratio of the cross-head displacement (after subtraction of machine compliance, see Section 3.2) to the original height of each sample (Table 1), and the nominal stress is defined as the applied load divided by the original cross-sectional area of each sample. 
The elastic modulus is determined as the averaged unloading stress-strain slope between $30 \%-70 \%$ of the stress at which the unloading starts (Sun et al., 2016a). The maximum strain attained in the compression test was $20 \%$ and twelve unloading-reloading cycles were performed in each test.

The testing machine has a relatively low load capacity $(10 \mathrm{kN})$ and it is necessary to accurately consider the effect of machine compliance on the compressive deformation measurement. The machine compliance was measured through a compression test without any sample between the two platens (Kalidindi et al., 1997). The measured compressive force-displacement of the testing machine was fitted using a power function to facilitate the elimination of the machine compliance from the cross-head displacement recorded during the compression test. It has been demonstrated that such a method is convenient and accurate for the measurement of elastic modulus of aluminium foams, with accuracy similar to that based on laser displacement sensor (Triawan et al., 2012).

\section{Results}

\subsection{Cut-surface profile and roughness}

Fig. 1 shows the cut surfaces of the foam samples prepared using EDM, BS and WJ. Three types of mesoscopic structural components can be identified, i.e. cell walls, nodes and facets, which were focused for the determination of local roughness (i.e. only the points on the cell walls, nodes and facets were considered as the measurement points in ROI). It should be noted that these mesoscopic structural components are defined according to the 2D morphological features within the cut surfaces. The cell walls are the aluminium membranes separating different cells, the nodes are the junctions of cell walls (typically three or four cell walls connect at one node on the cut surface), and the facets are the torn aluminium membranes aligning within the cut surface due to the tearing force applied during mechanical cutting. The facets only exist on the cut surfaces produced by BS and WJ. Cell walls and nodes exist on all cut surfaces and they are intrinsic structural components of closed-cell aluminium foam. 

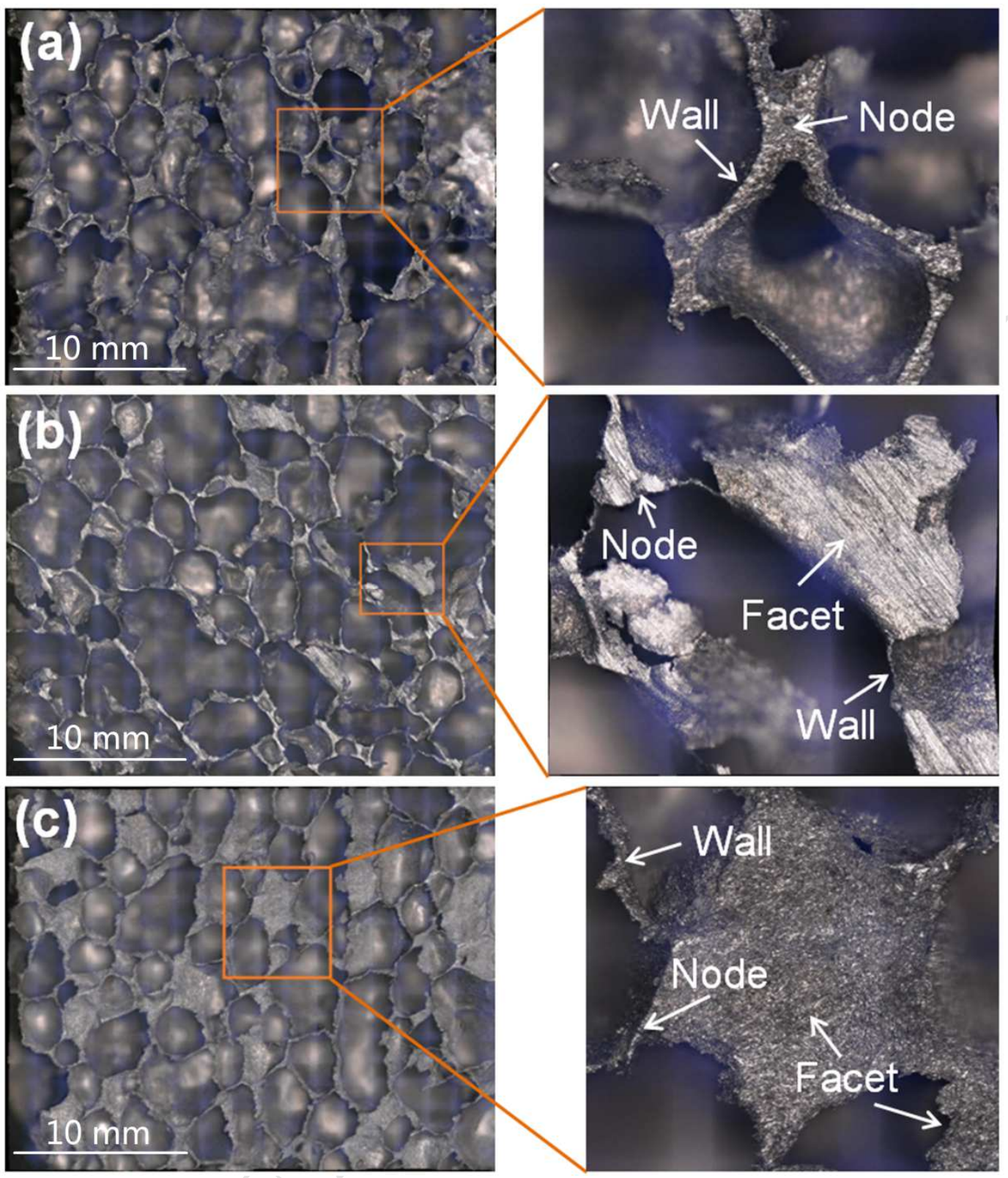

Fig. 1. Cut surfaces on the axial ends, of which the normal directions are parallel to the compression direction, for foam samples prepared by EDM (a), BS (b) and WJ (c). The locations and typical features of cell walls, nodes and facets are indicated.

Fig. 2 shows the local height of the three types of mesoscopic structural components constituting the cut surface produced by WJ, as an example for demonstration. The features of roughness are clearly seen in the cell walls, nodes and facets. The average roughness was obtained using the measurement data for the structural components at twenty different locations, based on Eqs. (1) and (2). Table 5 shows the measured local roughness. It is evident that EDM, BS and WJ produced cut surfaces with smallest, intermediate and largest local 
roughness values, respectively. It is also noticed that the EDM cutting minimises the deviation of local roughness between different locations for each structural component, while BS and WJ cutting processes cause significant scatters of the local roughness.

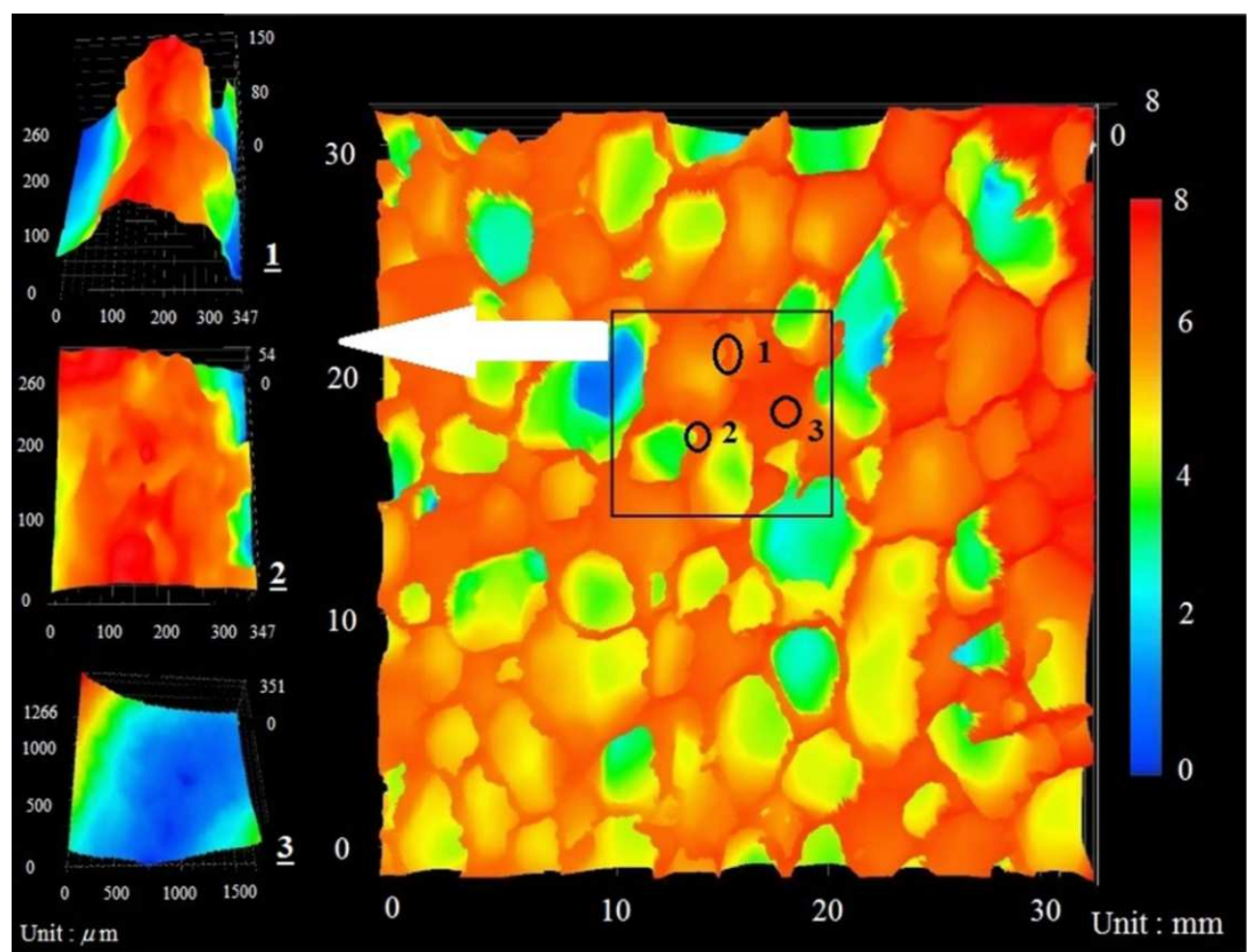

Fig. 2. Local height of mesoscopic structural components (1: cell wall; 2: node; 3: facet) of a WJ-cut sample.

Table 5 Local roughness of mesoscopic structural components constituting cut surface.

\begin{tabular}{ccc}
\hline Cutting method & Component & Roughness $(\mu \mathrm{m})$ \\
\hline \multirow{2}{*}{ EDM } & Cell wall & $4.8 \pm 2.6$ \\
& Node & $5.4 \pm 2.6$ \\
\hline \multirow{2}{*}{ BS } & Cell wall & $4.5 \pm 3.3$ \\
& Node & $6.8 \pm 6.5$ \\
& Facet & $9.2 \pm 6.9$ \\
\hline \multirow{2}{*}{ WJ } & Cell wall & $9.2 \pm 4.5$ \\
& Node & $14.8 \pm 11.7$ \\
& Facet & $15.3 \pm 11.4$ \\
\hline
\end{tabular}

Fig. 3 shows the 3D topography and linear distributions of local height across the entire 
cut-surfaces of foam samples. Through different lines drawn across the entire cut-surface, the global roughness can be obtained using Eqs. (1) and (2). Table 6 summarises the global roughness of cut surfaces produced by different cutting methods and it shows that, the smallest, intermediate and largest global roughness was produced by EDM, BS and WJ cutting processes, respectively, which are consistent with the local roughness results (Table 5). It is also observed that the cut surface produced by WJ (Fig. 3c) is somewhat inclined with respect to a horizontal loading platen (the inclination is schematically shown in Fig. 3c), in contrast to the overall flat cut-surfaces produced by EDM (Fig. 3a) and BS (Fig. 3b).
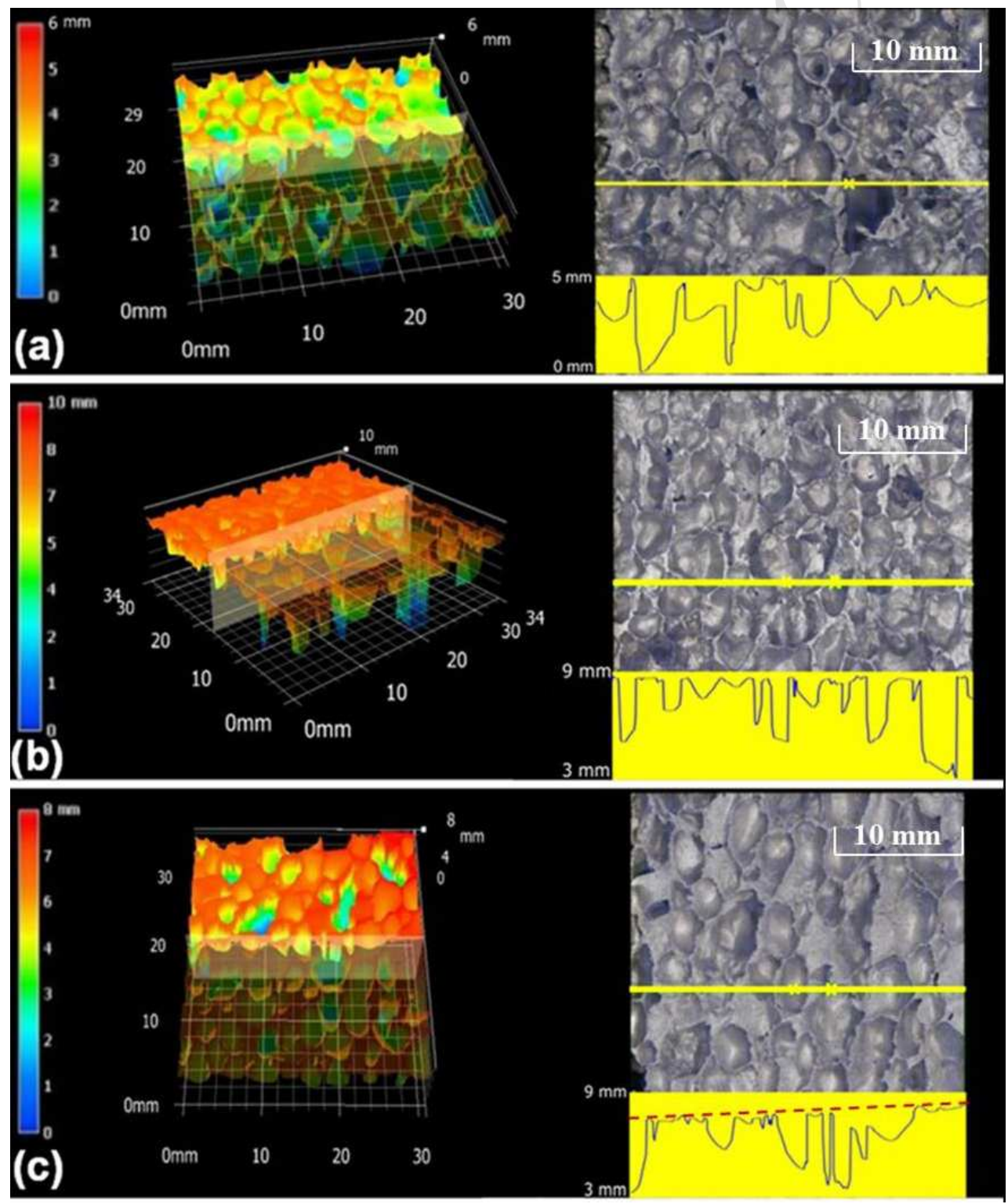

Fig. 3. Contours and line-profiles of local height of cut surfaces on the axial ends of foam samples prepared by EDM (a), BS (b) and WJ (c). 
Table 6 Global roughness of cut surfaces produced by different cutting methods

\begin{tabular}{cccc}
\hline Cutting method & EDM & BS & WJ \\
\hline Roughness $(\mu \mathrm{m})$ & 5.1 & 6.8 & 13.1 \\
\hline
\end{tabular}

\subsection{Compressive stress-strain relationship}

Fig. 4 shows the compressive force-displacement curve of the testing machine without adding any sample. A data fitting was performed using a power function, viz.

$$
d=A \cdot F^{n}
$$

where $d$ is machine displacement $(\mathrm{mm}), F$ is applied force $(\mathrm{N}), n$ is exponent and $A$ is a coefficient $\left(\mathrm{N}^{-n} \cdot \mathrm{mm}\right)$. For the testing machine used here, the data fitting $\left(R^{2} \approx 1.000\right)$ yields $n=0.79$ and $A=4.1 \times 10^{-4} \mathrm{~N}^{-0.79} \cdot \mathrm{mm}$. Subsequently, the actual shortening of the foam sample during the compression test can be conveniently obtained through subtracting the machine displacement calculated by Eq. (3) from the experimentally recorded cross-head displacement.

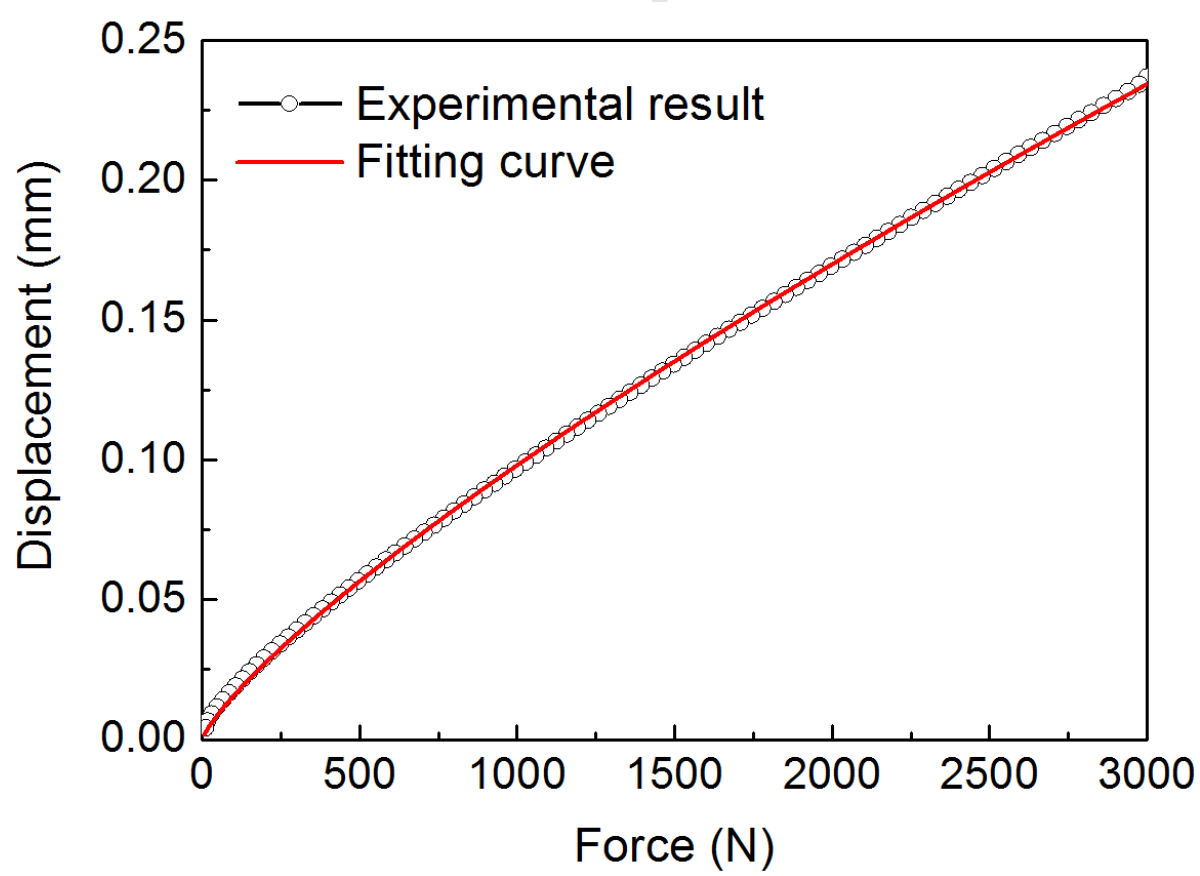

Fig. 4. Compressive displacement-force relationship of testing machine.

Fig. 5 shows the compressive stress-strain curves of the foam samples with a height of 20 $\mathrm{mm}$. A difference between the initial loading slope and subsequent unloading slope is clearly 
seen and the former is much smaller than the latter, which is particularly pronounced for the foam samples prepared by WJ cutting (Fig. 5c). It also appears that the initial loading slope is highest for the EDM-cut samples and lowest for the WJ-cut samples, while that for BS-cut samples is intermediate. In contrast, the peak and plateau of compressive stress are similar between the samples prepared by different cutting methods. Considerable scatter in compressive stress-strain curves is observed, which can be attributed to both the scatter in relative density (Table 1) and the inherent heterogeneity of foam structures (Ramamurty and Paul, 2004; Sun et al., 2017). Fig. 6 shows the compressive stress-strain curves of the foam samples with a height of $40 \mathrm{~mm}$. Apparently similar results were obtained, except that the initial loading slopes of the 40-mm height samples prepared by WJ cutting are markedly larger than those of the 20-mm height samples, as shown in Figs. 5c and 6c.

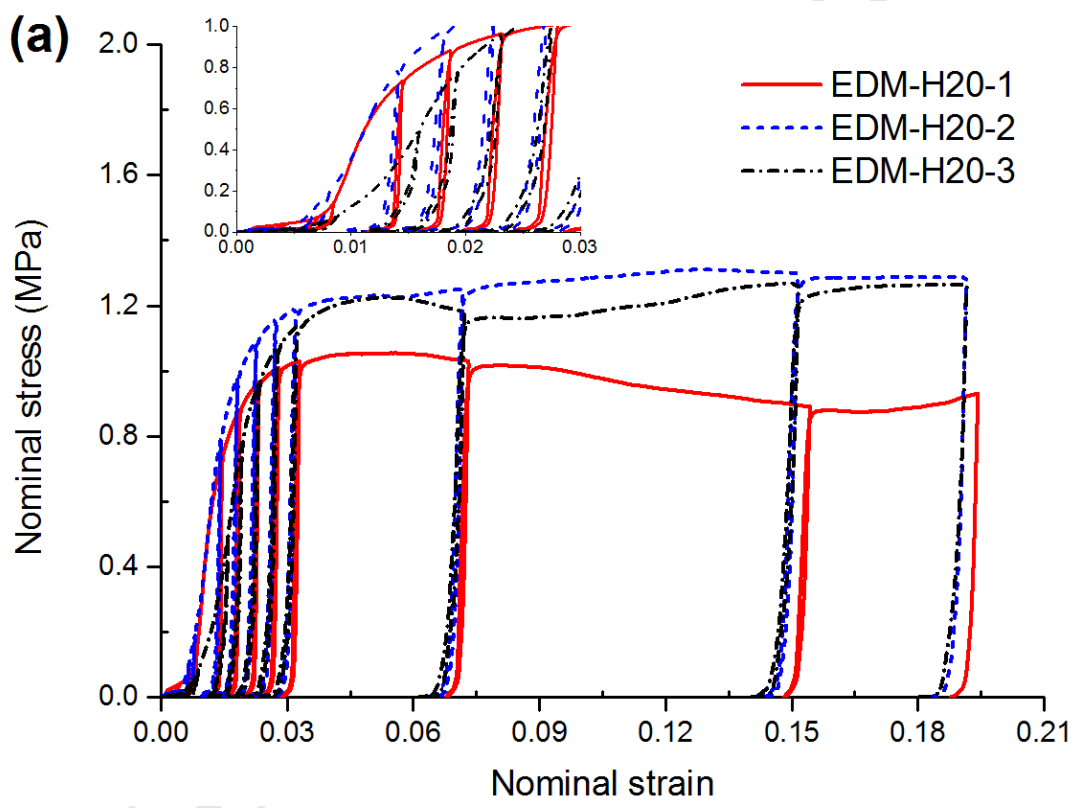



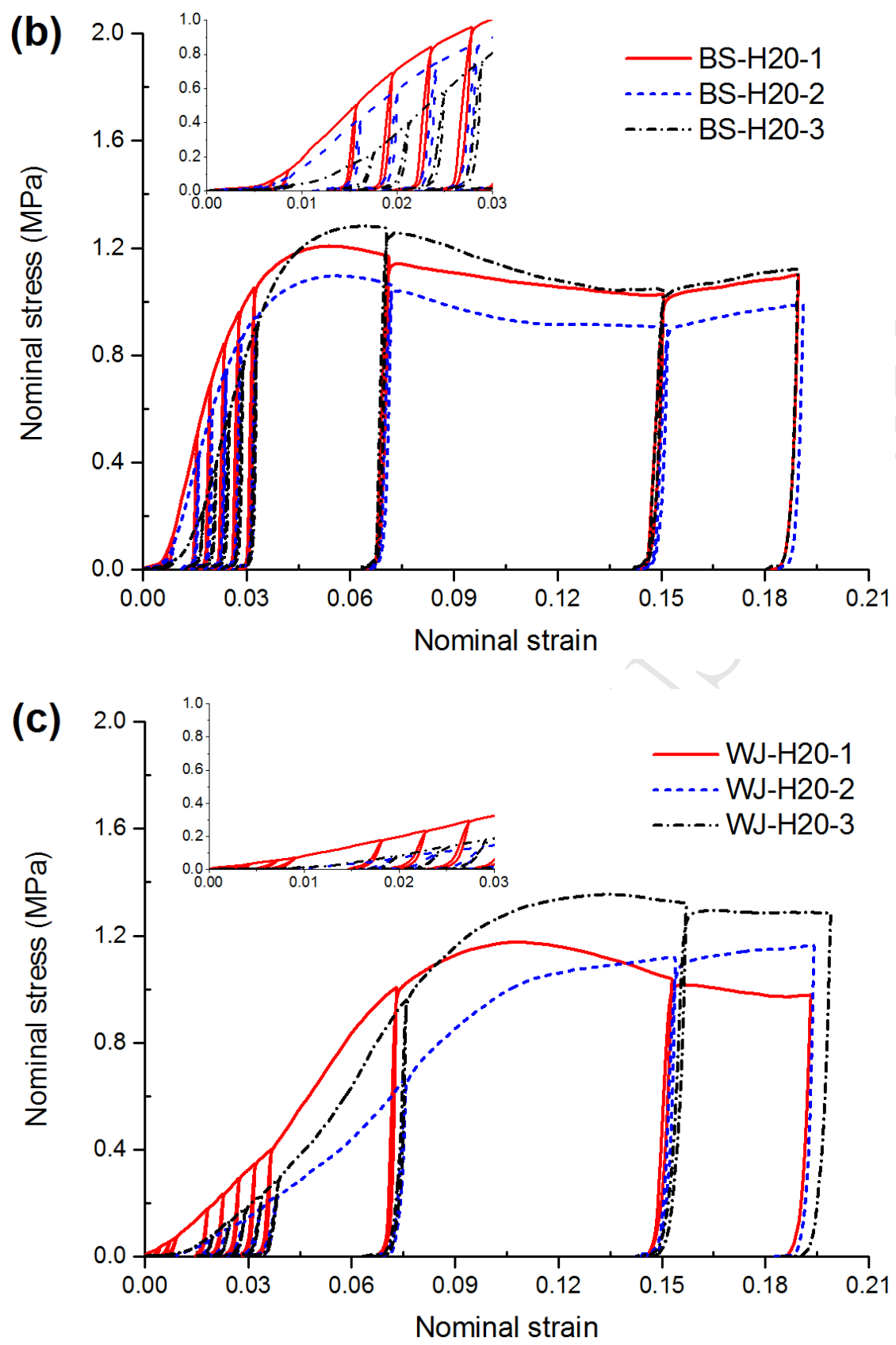

Fig. 5. Compressive stress-strain curves of foam samples with a height of $20 \mathrm{~mm}$ produced by different cutting methods: (a) EDM; (b) BS; (c) WJ. 

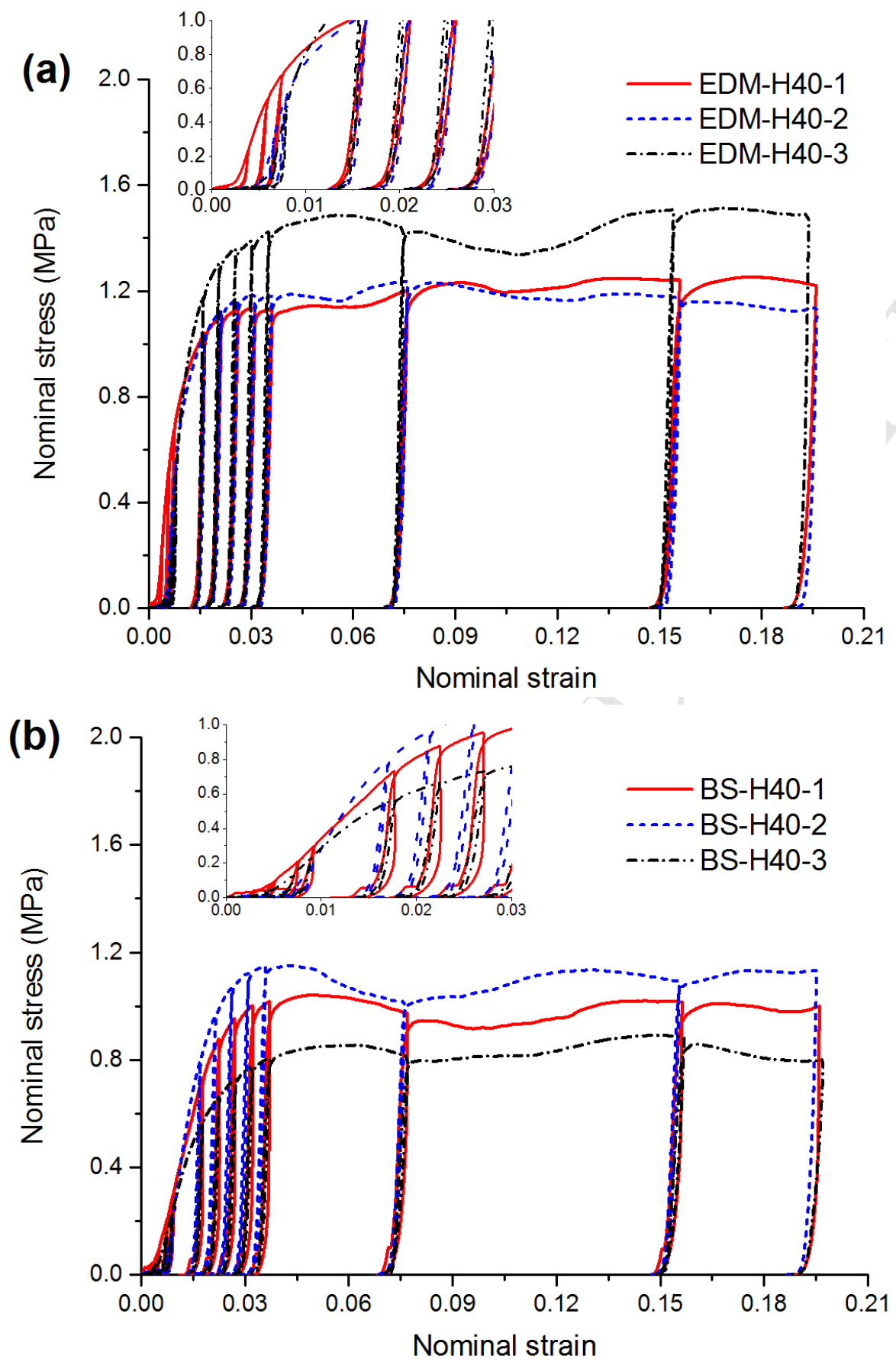


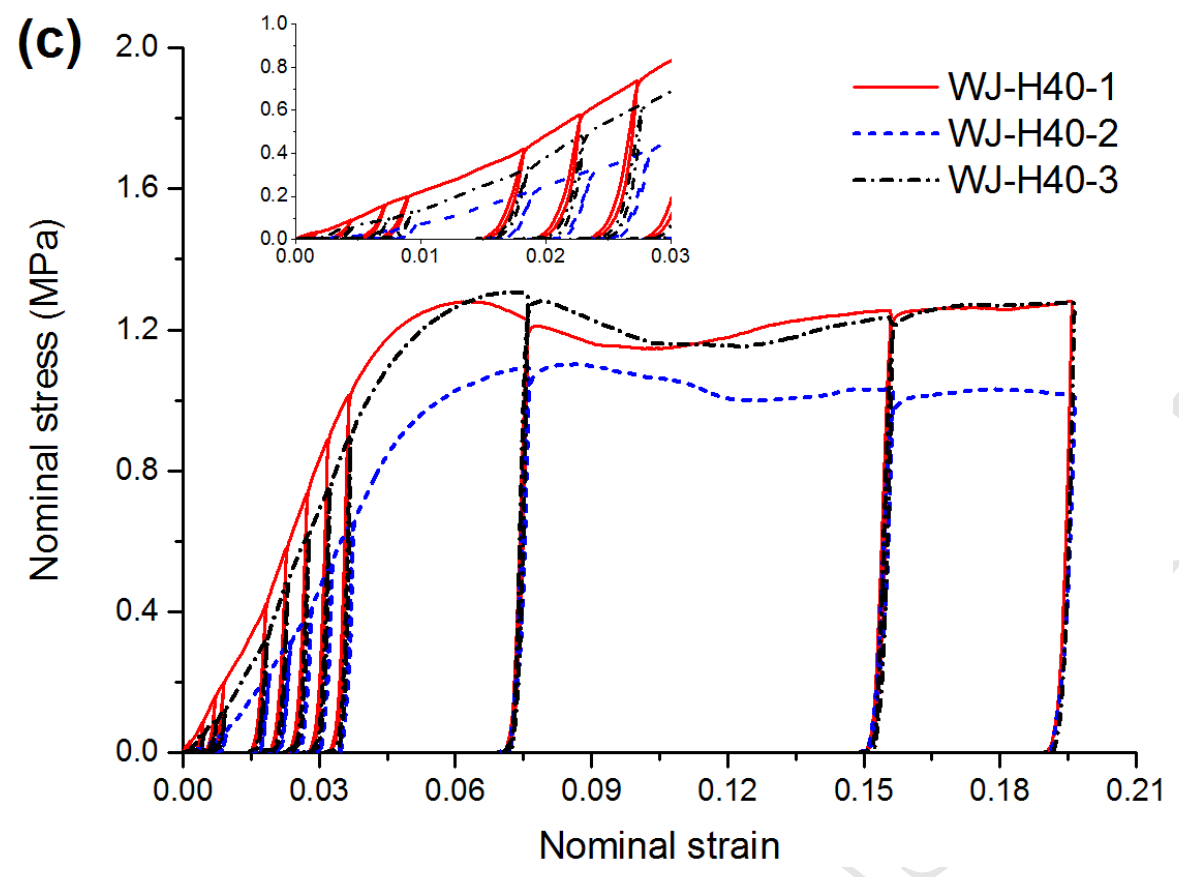

Fig. 6. Compressive stress-strain curves of foam samples with a height of $40 \mathrm{~mm}$ produced by different cutting methods: (a) EDM; (b) BS; (c) WJ.

\subsection{Compressive strength}

Table 7 shows the measured peak and plateau stresses of the foam samples produced by different cutting methods. To eliminate the effect of scatter in relative density, the following equation is used to normalise the compressive strength (Ashby et al., 2000)

$$
C_{\mathrm{C}}=\frac{\sigma_{\mathrm{c}}}{\sigma_{\mathrm{Y}}\left[0.5\left(\rho / \rho_{\mathrm{s}}\right)^{2 / 3}+0.3\left(\rho / \rho_{\mathrm{s}}\right)\right]}
$$

where $\sigma_{\mathrm{c}}$ is the compressive strength (i.e. peak stress or plateau stress), $\sigma_{\mathrm{Y}}$ is the yield strength of base material and $\rho / \rho_{\mathrm{s}}$ is the relative density. It is evident that the effect of cutting method on the peak and plateau stresses (either absolute or normalised value) is not significant, given the scatter caused by the heterogeneity of cell structure of Alporas foam (Ramamurty and Paul, 2004; Saadatfar et al., 2012). 
Table 7 Peak and plateau stresses of foam samples prepared by different cutting methods

\begin{tabular}{ccccccccc}
\hline & \multicolumn{3}{c}{$20 \times 40 \times 40-m m$ samples } & \multicolumn{3}{c}{$40 \times 40 \times 40-m m$ samples } \\
& $\begin{array}{c}\text { Peak Stress } \\
\text { Absolute } \\
\text { (MPa) }\end{array}$ & Normalised & $\begin{array}{c}\text { Plateau Stress } \\
\text { Absolute } \\
(\text { MPa) }\end{array}$ & Normalised & $\begin{array}{c}\text { Peak Stress } \\
\text { Absolute } \\
(\text { MPa })\end{array}$ & Normalised & $\begin{array}{c}\text { Plateau Stress } \\
\text { Absolute } \\
(\text { MPa })\end{array}$ & Normalised \\
\hline EDM-1 & 1.06 & 0.105 & 0.95 & 0.094 & 1.25 & 0.124 & 1.21 & 0.120 \\
EDM-2 & 1.31 & 0.113 & 1.28 & 0.111 & 1.19 & 0.109 & 1.18 & 0.108 \\
EDM-3 & 1.27 & 0.128 & 1.22 & 0.123 & 1.52 & 0.138 & 1.44 & 0.131 \\
BS-1 & 1.22 & 0.112 & 1.09 & 0.100 & 1.04 & 0.103 & 0.98 & 0.097 \\
BS-2 & 1.10 & 0.107 & 0.98 & 0.095 & 1.15 & 0.107 & 1.10 & 0.102 \\
BS-3 & 1.28 & 0.121 & 1.22 & 0.115 & 0.89 & 0.082 & 0.83 & 0.077 \\
WJ-1 & 1.18 & 0.111 & 1.06 & 0.100 & 1.28 & 0.122 & 1.22 & 0.116 \\
WJ-2 & 1.16 & 0.101 & 1.11 & 0.096 & 1.10 & 0.096 & 1.03 & 0.090 \\
WJ-3 & 1.36 & 0.121 & 1.31 & 0.117 & 1.30 & 0.117 & 1.22 & 0.110 \\
\hline
\end{tabular}

\subsection{Unloading elastic modulus}

Fig. 7 shows the measured unloading elastic moduli of the foam samples prepared by different cutting methods. A significant variation of the elastic modulus with strain is clearly seen, and there is a rapid increase in the modulus at strains smaller than a critical strain (e.g. $\sim 0.015$ for EDM-cut samples) and then a gradual decrease in the modulus at larger strains. Despite the scatter in the experimental data, it is evident that the measured moduli of the foam samples prepared by EDM cutting are markedly larger than those of the BS-cut and WJ-cut samples, although they have similar relative densities (Table 1). Interestingly, with increasing strain, the measured moduli tend to converge and the difference in modulus between the foam samples is reduced. It is also seen that increasing sample height from $20 \mathrm{~mm}$ to $40 \mathrm{~mm}$ leads to an overall increase in measured moduli. Although increasing height of a sample means increasing the number of cells along loading direction, the effect of the number of cells in the sample is minor for the dimensions of the Alporas foam samples used here (Jeon and Asahina, 2005) and cannot explain the observed increase in modulus, particularly for the WJ-cut samples. Exceptional reduction in modulus was also observed in a few samples (e.g. BS-H40-2 and BS-H40-3) when the height increases. Besides the scatter in the relative density (Table 1), the cause of the exceptionally reduced modulus for the 40-mm height samples (e.g. BS-H40-2 and BS-H40-3) could be associated with the heterogeneity of cell structure, which gives rise to scatter in bulk properties. Previous studies have shown that the compressive properties are sensitive to the weakest site which is controlled by the non-uniformly distributed mesoscopic structural parameters of Alporas foam (Ramamurty and Paul, 2004; Saadatfar et al., 2012; Sun 
et al., 2017).
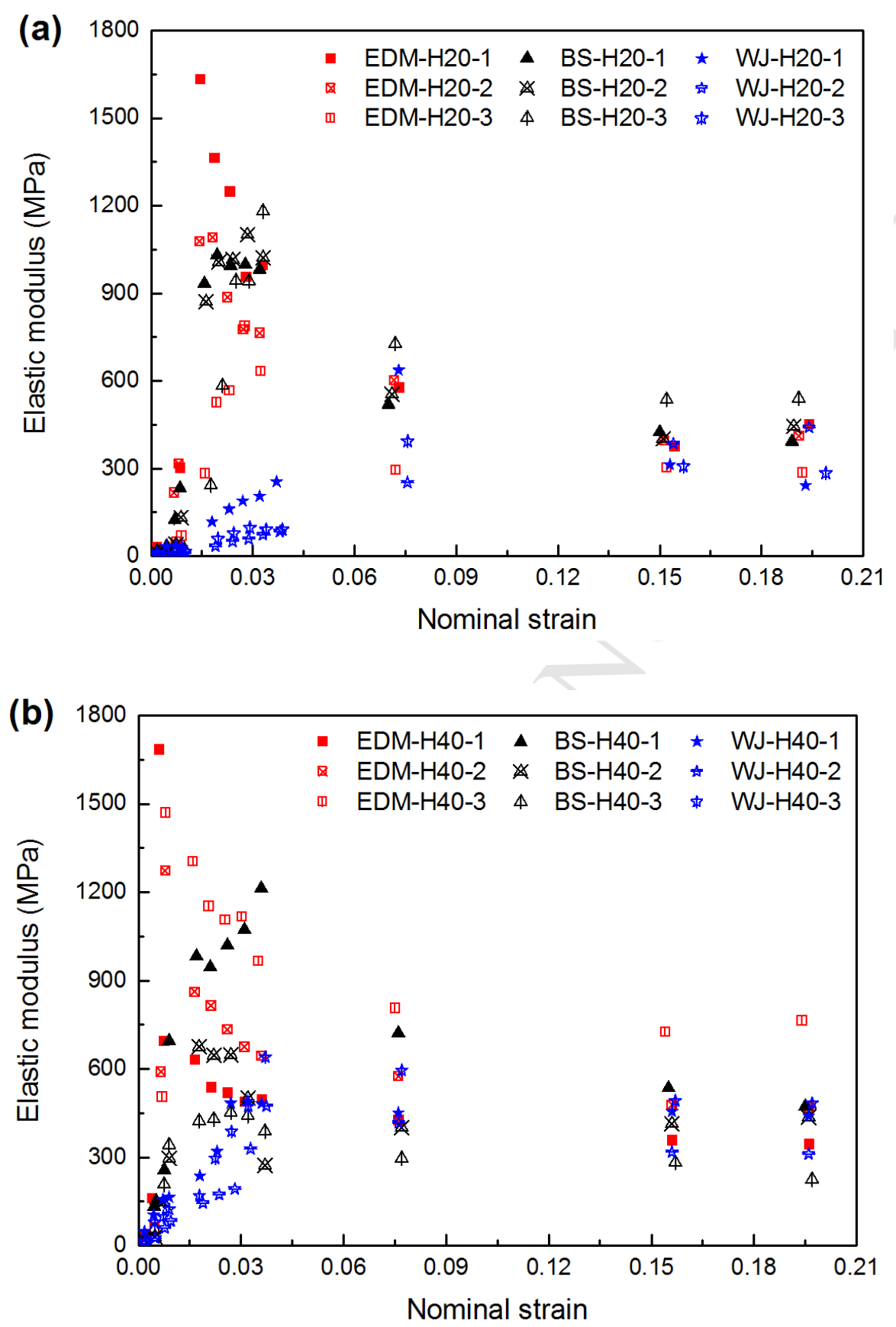

Fig. 7. Unloading elastic moduli of foam samples prepared by different cutting methods (i.e. EDM, BS and WJ) with height values of $20 \mathrm{~mm}$ (a) and $40 \mathrm{~mm}$ (b).

To exclude the effect of relative density, data normalisation is performed using following equation (Ashby et al., 2000)

$$
C_{\mathrm{E}}=\frac{E_{\mathrm{u}}}{E_{\mathrm{s}}\left[0.5\left(\rho / \rho_{\mathrm{s}}\right)^{2}+0.3\left(\rho / \rho_{\mathrm{s}}\right)\right]}
$$


where $E_{\mathrm{u}}$ is the unloading elastic modulus, $E_{\mathrm{s}}$ is the elastic modulus of base material, and $\rho / \rho_{\mathrm{s}}$ is the relative density. Fig. 8 shows the normalised results and a trend similar to that in Fig. 7 is clearly seen, confirming the effect of cutting method.
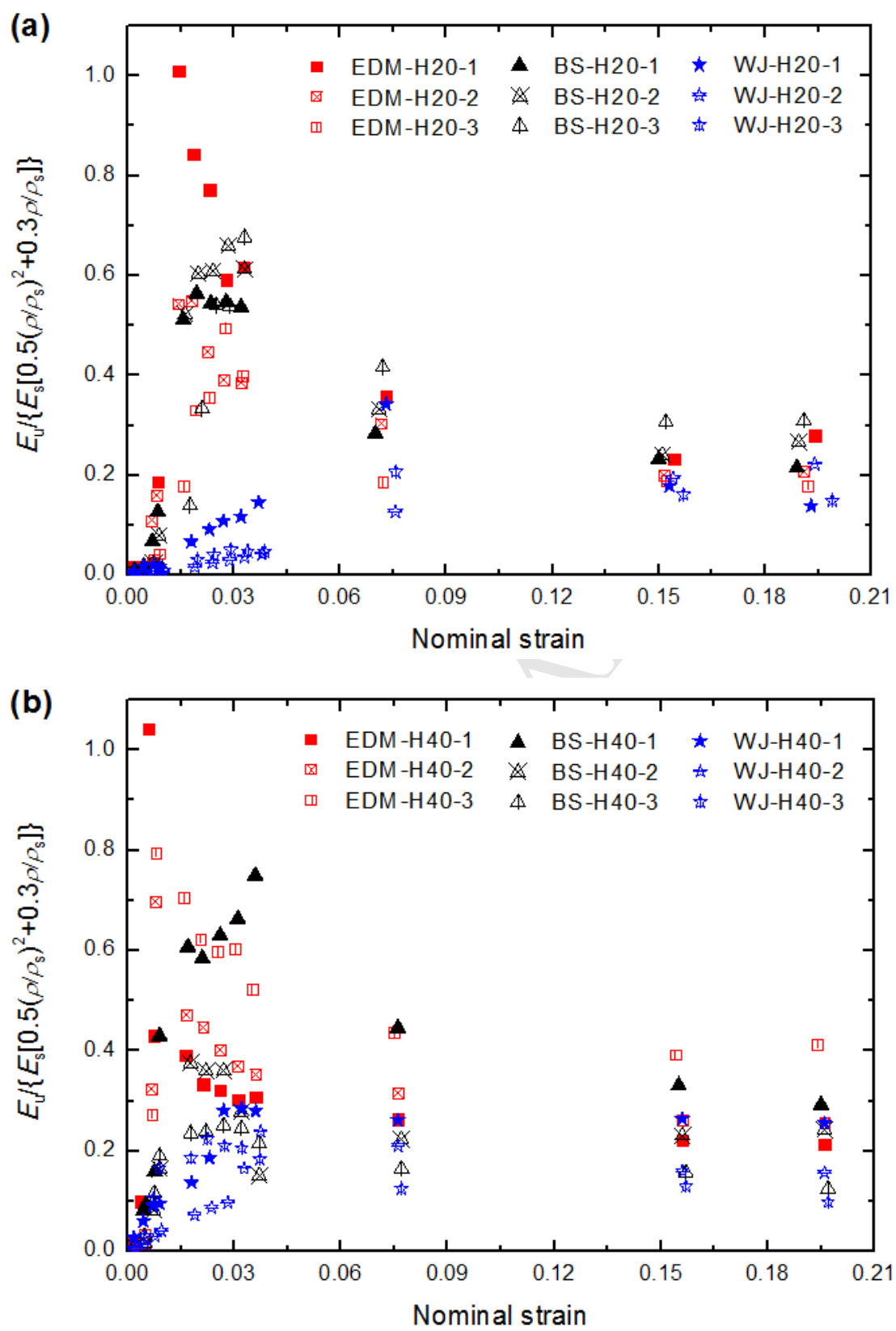

Fig. 8. Normalised unloading elastic moduli of foam samples prepared by different cutting methods (i.e. EDM, BS and WJ) with height values of $20 \mathrm{~mm}$ (a) and $40 \mathrm{~mm}$ (b).

\section{Discussion}

The characterisation of cut surfaces shows differences in both local and global roughness for Alporas foam samples produced by EDM, BS and WJ, as shown in Figs. 2 and 3, and Tables 5 and 6. These differences can be attributed to the distinctive thermal and mechanical 
response involved in the cutting processes, i.e. material distortion occurs during BS and WJ cutting processes which cause plastic tearing and ductile cracking, while EDM cutting is an electric-thermal process and causes little mechanical deformation. According to the measurement data (Figs. 2 and 3, and Tables 5 and 6), smallest and largest roughness values are found on the cut surfaces produced by EDM and WJ, respectively, while intermediate roughness is found on the BS cut surface. An overall slight inclination of cut surface is also observed in the foam samples prepared by WJ cutting (Fig. 3c), mainly due to the difference in the cutting effect between the entry and exit of the jet flow of high-pressure water (Kovacevic, 1991).

It is widely believed that cut-surface quality of sample ends affects measured compressive properties of foam materials (Anderson and Lakes, 1994; Ashby et al., 2000), but such an effect has been rarely examined quantitatively in experiment. Our experimental results show that the measured initial loading stiffness and subsequent unloading elastic modulus are sensitive to the roughness of the cut surface, as shown in Figs. 7 and 8, although a less sensitivity is found for the peak and plateau of compressive stress, as shown in Table 7. Despite the measurement scatter associated with the stochastic nature of foam structure, the differences in the loading stiffness and unloading modulus are evident between the foam samples prepared by different cutting methods, particularly when the results of EDM-cut samples are compared with those of WJ-cut samples, as shown in Figs. 5-8. Such differences are significant even when the mesoscopic structural scatter (e.g. local density variation) in foam samples is considered. Previous 3D characterisation of Alporas foam using X-ray tomography showed that the axial variation in the local relative density of Alporas foam is less than $3 \%$ (Saadatfar et al., 2012), and similar observation was reported by Sun et al. (2017) who analysed the local relative density distribution using X-ray tomography slice of Alporas foam. Therefore, the stochastic variation in local relative density cannot be the cause of the observed significant differences in the measured compressive properties shown in Figs. 5-8. In fact, the cutting-induced end surface effect plays a major role and there is a good correlation between cut-surface roughness and measured compressive properties. For instance, the EDM cutting leads to smallest roughness of cut surface (Tables 5 and 6), and consequently, the foam samples prepared by this method exhibit highest initial loading stiffness and unloading elastic modulus, 
whereas the WJ-cut samples with largest cut-surface roughness possess lowest measured compressive properties, as shown in Figs. 5-8.

Previous numerical modelling of uniaxial compression of Alporas foam predicted that the initial loading and unloading slopes were identical when the two end surfaces of the sample were perfectly flat and the compressive loading was applied by directly prescribing axial displacement to the end nodes, although premature local yielding was found in the cell wall after a small critical compressive strain (Sun et al., 2016a). In addition, the previous modelling results showed a continuous decrease in unloading elastic modulus with strain (Sun et al., 2016a). These previous numerical results are inconsistent with the experimental results obtained by Sun et al. (2016a) and those obtained here, as shown in Figs. 5-8. Sun et al. (2016a) have proposed mesoscopic mechanisms to explain the phenomena and to guide accurate measurements of compressive properties. Here, an analytical model is developed to further understand the unique behaviour of closed-cell aluminium foam in the initial stage of compression.

From mechanics point of view, the roughness and damage induced by cutting give rise to two end-surface layers possessing much lower stiffness and strength in comparison with the main body of the foam sample. This effect is more pronounced for closed-cell foams than traditional structural materials, since the former have thin/delicate membranes and high porosity. For the end-surface layers (top and bottom), the following constitutive law can be assumed

$$
\begin{array}{ll}
\varepsilon_{\text {surf }}=\frac{\sigma}{E_{\text {surf }}} & \sigma<\sigma_{\text {Ysurf }} \\
\varepsilon_{\text {surf }}=\frac{\sigma_{\text {Ysurf }}}{E_{\text {surf }}}\left(\frac{\sigma}{\sigma_{\text {Ysurf }}}\right)^{m} & \sigma \geq \sigma_{\text {Ysurf }}
\end{array}
$$

where $\varepsilon_{\text {surf }}, E_{\text {surf }}, \sigma_{\text {Ysurf }}$ and $m$ are the engineering strain, elastic modulus, compressive strength and strain hardening exponent $(>1)$ of the end-surface layers, respectively. Furthermore, it is assumed that the global deformation of the foam sample can be divided between the end-surface layers and the main body, and elastic deformation is dominant in the main body during the initial compression. When the yielding (or failure) of end-surface layers occurs immediately after loading (Sun et al., 2016a), the global compressive strain can be expressed as

$$
\varepsilon=\frac{2 h}{H} \frac{\sigma_{\text {Ysurf }}}{E_{\text {surf }}}\left(\frac{\sigma}{\sigma_{\text {Ysurf }}}\right)^{m}+\left(1-\frac{2 h}{H}\right) \frac{\sigma}{E}
$$


where $h, H$ and $E$ are the end-surface layer thickness, the sample height and the elastic modulus of main body, respectively. Then the elastic strain component is obtained as

$$
\mathcal{E}^{\mathrm{e}}=\frac{2 h}{H} \frac{\sigma}{E_{\text {surf }}}+\left(1-\frac{2 h}{H}\right) \frac{\sigma}{E}
$$

Noting $E_{\mathrm{u}}=\mathrm{d} \sigma / \mathrm{d} \varepsilon^{\mathrm{e}}$ (unloading elastic modulus) and $S_{\mathrm{L}}=\mathrm{d} \sigma / \mathrm{d} \varepsilon$ (loading stiffness), we have the following dimensionless equations

$$
\frac{E_{\mathrm{u}}}{E}=\left[1+\frac{2 h}{H}\left(\frac{E}{E_{\text {surf }}}-1\right)\right]^{-1}
$$

and

$$
\frac{E_{\mathrm{u}}}{S_{\mathrm{L}}}=\left\{1+\frac{2 h}{H}\left[m\left(\frac{\sigma}{\sigma_{\text {Ysurf }}}\right)^{m-1} \frac{E}{E_{\text {surf }}}-1\right]\right\} /\left[1+\frac{2 h}{H}\left(\frac{E}{E_{\text {surf }}}-1\right)\right]
$$

Since $E>E_{\text {surf }}, \sigma>\sigma_{\text {Ysurf }}$ and $m>1$, the above equations predict that $E_{\mathrm{u}}$ is smaller than $E$ but larger than $S_{\mathrm{L}}$, and such differences can be significant if $E$ is much larger than $E_{\text {surf }}$ and $\sigma$ is much larger than $\sigma_{\text {Ysurf }}$. From Eq. (10), we also see that $E_{\mathrm{u}}$ will approach to $E$ when $E_{\text {surf }}$ increases with strain due to operative hardening mechanisms (e.g. local cell-wall stiffening in contact with loading platens). The above analysis explains the reason why the experimentally determined unloading elastic modulus is larger than the initial loading stiffness and increases from a small value at the very beginning of the compression, as shown in Figs. 5-8. Given the explanation offered by a continuum mechanics model, it should be pointed out that the variation in the macroscopic compressive properties actually reflects a series of complicated deformation processes occurring at both micro- and meso-scales (Sun et al., 2016a; Sun and Li, 2018; Sun et al., 2017; Sun et al., 2014).

The EDM cutting produces smallest roughness of cut surface, which implies that more base-material, relative to BS-cut and WJ-cut samples, can contribute to the compressive load resistance when the loading platen contacts with the sample end. Therefore, the $E_{\text {surf }}$ and $\sigma_{\text {Ysurf }}$ for EDM-cut samples are larger than those for BS-cut and WJ-cut samples, and the difference is particularly significant between the EDM-cut and WJ-cut samples. Furthermore, according to Eqs. (10) and (11), the initial loading stiffness and unloading elastic modulus of EDM-cut samples are highest among all the tested samples. However, it is not feasible to establish the quantitative dependence of $E_{\text {surf }}$ and $\sigma_{\text {Ysurf }}$ on roughness, since the $E_{\text {surf }}$ and 
$\sigma_{\text {Ysurf }}$ are unlikely to be directly measured. Eqs. (10) and (11) also predict that increasing sample height (i.e. decreasing $h / H$ ) increases the measured initial loading stiffness and unloading elastic modulus, due to the reduced contribution of weak end-surface layers to the measured bulk properties. These predictions based on Eqs. (10) and (11) are all consistent with experimental results shown in Figs. 5-8.

Eqs. (10) and (11), however, do not imply that the cells on the sample ends should always collapse first, particularly when the foam sample is prepared by EDM cutting (Bastawros et al., 2000). The reason is twofold. Firstly, when an optimal cutting is performed, the roughness and damage of the cut surface can be minimised and then the compressive properties of the end-surface layer will approach those of the main body. This has been confirmed by simulation of ideal compression of Alporas foam using 3D cell-based models (Sun et al., 2016a; Sun et al., 2016b). Secondly, although the two end-surface layers that are produced by a cutting process possess relatively low elastic modulus and yield strength, they exhibit fast stiffening and hardening during the establishment of the contact between the loading platen and foam sample. This also explains the observation that the peak and plateau stresses, which correspond to relatively large strains, are insensitive to cutting method, as shown in Table 7. Therefore, the cutting-induced end surface effect is limited to the initial compression. With strain increasing further, the unloading elastic modulus decreases, which is due to the extensive local yielding and the progressive crushing in the main body (Sun et al., 2016a). With the knowledge of this fact, it is unsurprising to see that the measured unloading elastic moduli of the foam samples prepared by different cutting methods are similar in the plateau stage (Figs. 7 and 8).

It should be noted that the quality of the lateral cut-surfaces does not affect the measured uniaxial compressive properties, since the side-surface layers do not contribute to the uniaxial compressive load resistance (Tekoğlu et al., 2011). Also note that the mechanisms elucidated here are associated with cut-produced end-surface layers; they are different from the effect of the number of cells (i.e. sample size divided by cell size) in a foam sample on the measured compressive properties.

\section{Conclusions}

The end-surface characterisation shows that both local and global roughness values are smallest for EDM-cut samples, largest for WJ-cut samples and intermediate for BS-cut samples. The difference in roughness greatly impacts the measured initial loading stiffness and unloading elastic modulus of the aluminium Alporas foam. The quasi-static uniaxial 
compression test results show that the EDM-cut samples possess highest initial loading stiffness and unloading elastic modulus, followed by the BS-cut and WJ-cut samples. These differences in the measured compressive properties between the foam samples prepared by the three cutting methods are attributed to the corresponding difference in the roughness of cut surface. In contrast, the peak and plateau of compressive stress are hardly affected by the roughness of cut surface. In the plateau stage, the unloading elastic modulus is also insensitive to cutting method. Furthermore, it is found that the increase of sample height leads to the reduction of the effect of cut surfaces at sample ends and the improvement of the measurement accuracy of bulk properties for the initial compression stage, and therefore, the measurements can give better representations of the intrinsic properties of the aluminium foam. An analytical model has been also developed to qualitatively explain the cutting-induced end surface effect on the compressive behaviour of foam materials. The model elucidates that the initial loading and unloading slopes of the measured compressive stress-strain curve are affected by the cut-produced end-surface layers which possess initially inferior but fast stiffening/hardening elasto-plastic properties associated with cut-surface roughness.

\section{Acknowledgements}

The authors are grateful to T. Neild, K. Totton, A. Williams, D. Wilson and D. Mortimer for their technical assistance in experiment. The authors also appreciate the help from Y. Yan. The second author would like to acknowledge the financial support from China Scholarship Council (No.201604890006). The third author acknowledges the support from the Open Project (SV2018-KF-37) of China State Key Laboratory for Strength and Vibration of Mechanical Structures.

\section{References}

Anderson, W.B., Lakes, R.S., 1994. Size effects due to Cosserat elasticity and surface damage in closed-cell polymethacrylimide foam. Journal of Materials Science 29, 6413-6419.

Andrews, E., Gioux, G., Onck, P., Gibson, L., 2001. Size effects in ductile cellular solids. Part II: experimental results. International Journal of Mechanical Sciences 43, 701-713.

Ashby, M.F., Evans, A.G., Fleck, N.A., Gibson, L.J., Hutchinson, J.W., Wadley, H.N.G., 2000. Metal foams: a design guide. Elsevier.

Banhart, J., 2001. Manufacture, characterisation and application of cellular metals and metal foams. Progress in Materials Science 46, 559-632.

Banhart, J., García-Moreno, F., Heim, K., Seeliger, H., 2017. Light-weighting in transportation and defence using aluminium foam sandwich structures, International Symposium on Light Weighting for Defence, Aerospace and Transportation, Goa, India. 
Bastawros, A.F., Bart-Smith, H., Evans, A.G., 2000. Experimental analysis of deformation mechanisms in a closed-cell aluminum alloy foam. Journal of the Mechanics and Physics of Solids 48, 301-322.

Codolini, A., Li, Q.M., Wilkinson, A., 2017. Influence of machining process on the mechanical behaviour of injection-moulded specimens of talc-filled Polypropylene. Polym Test 62, 342-347.

Gibson, L.J., Ashby, M.F., 1997. Cellular solids: structure and properties, 2 ed. Cambridge University Press.

Gibson, L.J., Ashby, M.F., Harley, B.A., 2010. Cellular materials in nature and medicine. Cambridge University Press.

Hofmann, A., Kaudelka, S., 2016. Fire safety of facades with polystyrol foam insulation.

Islam, M., Kader, M., Brown, A., Hazell, P., Escobedo, J., Saadatfar, M., 2017. Experimental Investigation of Mechanical Behaviour of Closed-Cell Aluminium Foams Under Drop Weight Impact, Characterization of Minerals, Metals, and Materials 2017. Springer, pp. 225-232.

ISO, 1997. 4287:1997-Geometrical Product Specifications (GPS)-Surface Texture: Profile Method-Terms, Definitions and Surface Texture Parameters. International Organization for Standardization, Genève.

Jeon, I., Asahina, T., 2005. The effect of structural defects on the compressive behavior of closed-cell Al foam. Acta Materialia 53, 3415-3423.

Kalidindi, S.R., Abusafieh, A., El-Danaf, E., 1997. Accurate characterization of machine compliance for simple compression testing. Experimental Mechanics 37, 210-215.

Kovacevic, R., 1991. Surface texture in abrasive waterjet cutting. J Manuf Syst 10, 32-40.

Krajewski, S., Nowacki, J., 2013. Preparation of aluminium foam edges for welding. Advances in Materials Sciences 13, 64-75.

Krajewski, S., Nowacki, J., 2015. Structure of AlSi-SiC composite foams surface formed by mechanical and thermal cutting. Applied Surface Science 327, 523-531.

Lu, T.J., Hess, A., Ashby, M.F., 1999. Sound absorption in metallic foams. Journal of Applied Physics 85, 7528-7539.

Markaki, A., Clyne, T., 2001. The effect of cell wall microstructure on the deformation and fracture of aluminium-based foams. Acta Materialia 49, 1677-1686.

Miyoshi, T., Itoh, M., Akiyama, S., Kitahara, A., 2000. ALPORAS aluminum foam: production process, properties, and applications. Advanced engineering materials 2, 179-183.

Ramamurty, U., Paul, A., 2004. Variability in mechanical properties of a metal foam. Acta Materialia 52, 869-876.

Ryan, S., Christiansen, E.L., 2013. Hypervelocity impact testing of advanced materials and structures for micrometeoroid and orbital debris shielding. Acta Astronaut 83, 216-231.

Saadatfar, M., Mukherjee, M., Madadi, M., Schröder-Turk, G.E., Garcia-Moreno, F., Schaller, F.M., Hutzler, S., Sheppard, A.P., Banhart, J., Ramamurty, U., 2012. Structure and deformation correlation of closed-cell aluminium foam subject to uniaxial compression. Acta Materialia 60, 3604-3615.

Sugimura, Y., Meyer, J., He, M.Y., Bart-Smith, H., Grenstedt, J., Evans, A.G., 1997. On the mechanical performance of closed cell Al alloy foams. Acta Materialia 45, 5245-5259.

Sun, Y., Amirrasouli, B., Razavi, S.B., Li, Q.M., Lowe, T., Withers, P.J., 2016a. The variation in elastic modulus throughout the compression of foam materials. Acta Materialia 110, 161-174.

Sun, Y., Li, Q.M., 2018. Dynamic compressive behaviour of cellular materials: A review of phenomenon, mechanism and modelling. International Journal of Impact Engineering 112, 74-115.

Sun, Y., Li, Q.M., Lowe, T., McDonald, S.A., Withers, P.J., 2016b. Investigation of strain-rate effect on the compressive behaviour of closed-cell aluminium foam by $3 \mathrm{D}$ image-based modelling. Materials $\&$ Design 89, 215-224.

Sun, Y., Zhang, X., Shao, Z., Li, Q.M., 2017. Image-based correlation between the meso-scale structure and deformation of closed-cell foam. Materials Science and Engineering: A 688, 27-39. 
Sun, Y.L., Lowe, T., McDonald, S.A., Li, Q.M., Withers, P.J., 2014. In situ investigation and image-based modelling of aluminium foam compression using micro X-Ray computed tomography, Visual Computing: Scientific Visualization and Imaging Systems. Springer, pp. 189-197.

Tekoğlu, C., Gibson, L.J., Pardoen, T., Onck, P.R., 2011. Size effects in foams: Experiments and modeling. Progress in Materials Science 56, 109-138.

Triawan, F., Kishimoto, K., Adachi, T., Inaba, K., Nakamura, T., Hashimura, T., 2012. The elastic behavior of aluminum alloy foam under uniaxial loading and bending conditions. Acta Materialia 60, 3084-3093. 
- Closed-cell aluminium foam samples were prepared by three cutting methods

- Cut-surface roughness was measured using confocal microscopy

- Compressive behaviour was correlated with cut-surface characteristics on sample ends

- Analytical model was developed to elucidate the mechanisms 